\title{
A behavioral perspective on the governance of common resources
}

\author{
Marco A. Janssen \\ Center for the Study of Institutional Diversity \\ Arizona State University
}

\begin{abstract}
During the last forty years evidence from systematic case study analysis and behavioral experiments have provided a comprehensive perspective on how communities can manage common resources in a sustainable way. The conventional theory based on selfish rational actors cannot explain empirical observations. A more comprehensive theoretical framework of human behavior is emerging that include concepts such as trust, conditional cooperation, otherregarding preferences, social norms, and reputation. The new behavioural perspective also demonstrates that behavioral responses depend on social and biophysical context.
\end{abstract}

\section{Introduction}

One of the main key challenges in environmental sustainability is the governance of common resources. The 1968 essay by biologist Garrett Hardin [1] located the topic in the center of the increasing awareness of the human impact on the environment. Hardin envisioned a pasture open to all, in which each herder received an individual benefit from adding sheep to graze on the common land and suffered costs only later (costs that were shared with other herders) from overgrazing. The only two interventions proposed that would prevent overharvesting the commons were the establishment of private property rights or taxing the use of common resources. Hardin concluded that overuse of the commons was inevitable since users - assumed to be motivated by self-interest - will not self-organize.

Hardin's judgment became widely accepted due to its consistency with predictions from non-cooperative game theory, the economics of resource use, and well-noted examples of resource collapses [2, 3, 4]. The consequences of this work were significant. Hardin and others distinguished three types of property rights: communal, private and state. However, communal property was equated with the absence of exclusive and effective rights and thus an inability to govern the commons. From this perspective, sustainable use of shared resources was only possible when there was little demand or a low population density.

However, if Hardin was right, why are so many common resources not overharvested? In this paper we focus on the insights from behavioral studies that provide a better understanding why self-governance is possible. Those behavioral studies - mainly experimental - were motivated by stylized facts from comparative case study analysis.

\section{Meta-analysis of case studies}

In the mid-1980s, a group of interdisciplinary scholars who perform field studies began to discover that the empirical evidence was not consistent with conventional theory [5]. In order to understand the diversity of outcomes from individual case studies there was a need for synthesis. A large number of case studies were accumulated over the years that showed both successes and failures of self-organization of resource users. The resources included local fisheries, irrigation systems, pastures and forests. Elinor Ostrom [6], a political economist, was one of the leading forces during this period and, in 2009, won the Nobel Prize in economic sciences for her contributions on the study of the governance of common resources. She had developed the 
Institutional Analysis and Development (IAD) framework, which was one of the tools used to systematically organize the information from the many case studies available [7, 8*]. The IAD framework is a meta-theoretical framework that identifies action situations, patterns of interactions and outcomes, and an evaluation of these outcomes (Figure 1). The action situation is one in which people interact in various different ways, such as exchanging of goods, meeting, and deliberating.

\section{Exogenous Variables}

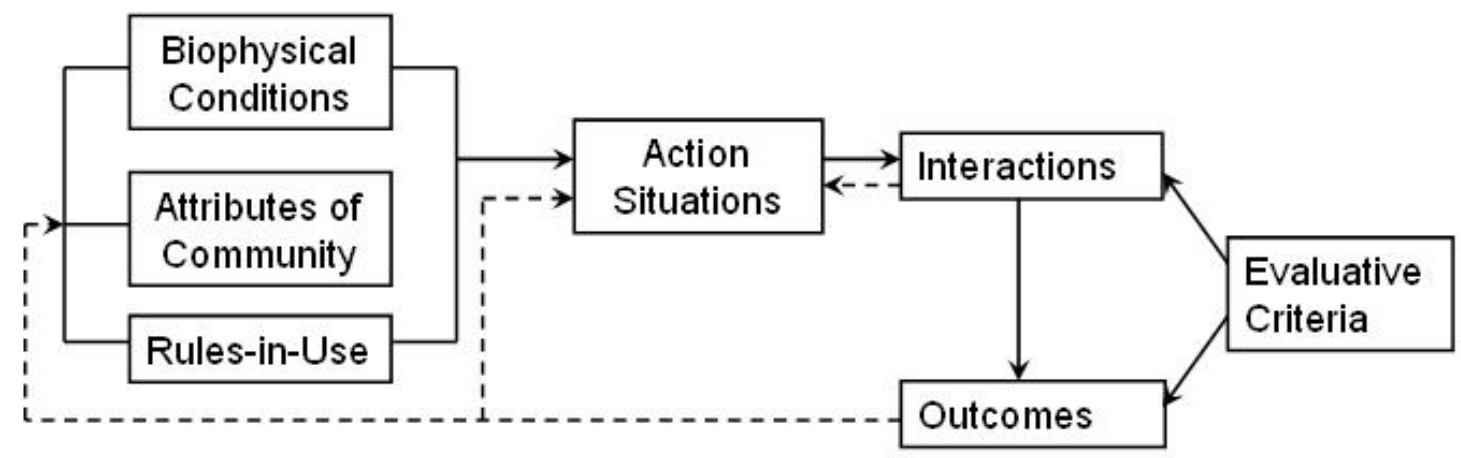

Figure 1: A framework for institutional analysis. Adapted from Ostrom [8*].

The action situation is influenced by contextual variables such as the biophysical attributes of a resource (e.g., size, spatial and temporal dynamics, predictability), the attributes of the community (e.g., size, heterogeneity) and the rules used by participants to govern their interactions. The interactions of participants lead to outcomes (e.g., state of the resource, distribution of income of participants). Participants can evaluate the outcomes of the interactions and may adjust their actions, including the rules in use.

The action situation acknowledges that people can have different positions such as consumer, producer, official, harvester, guard, etc. These positions can affect access to information and resources and therefore define some of the power differences in communities. The positions people hold in an action situation affect the actions they can take, such as whether they can give permits, are allowed to access the resource, etc. The outcomes are evaluated by their costs and benefits, realizing that these costs and benefits are not necessarily monetary in their nature.

The IAD framework (Figure 1) explicitly distinguishes rules-in-use in contrast to ruleson-paper. The reason for this is that it is more effective to study the actual behavior with relation to the common-pool resource. It is not necessarily the case that rules-on-paper are known or accepted by all participants in the system. Collecting information about the actual rules people use in their decision making is important to understand their motivations and incentives for the decisions they make. It will also be helpful to understand what actions are needed to avoid undesirable outcomes.

Ostrom [9] presented an initial analysis of a systematic effort to code hundreds of case studies of fisheries and irrigation systems. Originally the goal was to find the institutional arrangements that would lead to the best outcomes of the governance of common-pool resources. However, she was not able to specify rules that generated success. Instead she formulated a set of 
lessons learned, which she called design principles, that were generally found to be present in cases of successful governance of common-pool resources. These design principles included well-defined boundaries of resource systems and social groups, proportional equivalence between benefits and costs, collective-choice arrangements, implementation of effective monitoring of resource conditions and rule compliance, graduated sanctions, conflict-resolution mechanisms, and minimal recognition of rights. The final design principle is on nested enterprises when resources are part of a larger system, different nested layers should be organized to match the activities of the local users and the biophysical conditions.

The proposed design principles have been tested in many publications since Ostrom and they are well supported empirically [10]. This does not mean that other factors are not important. Future work will need to test what the main factors are in each circumstance.

\section{Experimental results}

The analysis of field studies shows that the conventional model of human behavior did not hold. People are able to govern their commons in sustainable ways without external interventions. In order to derive an alternative theory it is important to replicate the findings from field settings in more controlled situations. Since the late 1980s, laboratory and field experiments have been performed that confirm the insights from the field studies [11]. This is important for the development of theory since observations in field studies might be disregarded by some scholars as anecdotal. Replicating field observations in controlled experiments with diverse populations provides specific insights into what enhances the likelihood of self-governance of common-pool resources.

Hardin's prediction of the tragedy of the commons was demonstrated if participants cannot communicate or have any institutional arrangements to govern their common resources $\left[11,12^{*}\right]$. On average the participants harvest the level of earnings similar to the predicted Nash equilibrium [11]. However, if cheap talk or costly punishment is allowed, participants are able to derive much higher earnings as a group and avoid overharvesting. In cheap talk participants are allowed to communicate, face-to-face or in chat-rooms on the internet, but cannot enforce their agreements $[11,12 *]$. In the context of non-cooperative game theory, cheap talk is viewed as irrelevant and therefore the findings of Ostrom and colleagues on its effectiveness are remarkable [11]. The use of costly-punishment was observed in field studies, but was not consistent with the theory of norm-free, complete rational selfish behavior of actors [13]. In costly-punishment, users pay a fee to reduce the earnings of someone else [14]. It was shown that participants use costly punishment and that this leads to a reduction of the harvesting rate $\left[11,12^{*}\right]$. Recent studies on costly-punishment show that creating institutional arrangements due to centralized sanctioning mechanisms are more effective and sustainable compared to peer punishment $\left[15^{* *}, 16\right]$.

During the last few years more ecological complexity is included in experiments to capture non-linear effects, asymmetry and uncertainty [17, 18, 19, 20, 21, 22, 23, 24]. Main factors affecting cooperative behavior remain trust, conditional cooperation, communication and sanctioning. Additionally those studies show that the uncertainty affects cooperation - typically declines - and that the biophysical context can reduce information flows and therefore cooperation $[17,22,23]$.

These findings have been replicated by experiments in the field with traditional resource users like farmers and fishers. Those field experiments increases the external validity of results $\left[25^{* *}, 26\right]$. For example, experiments have been performed with forest resource users in rural 
Colombia [27]. Instead of talking about abstract resources, the experiment was framed as investing hours in collecting fuel wood from the common resource. The participants received a payoff table that helped them to make decision on how much time to spend in fuel wood extraction and how much for alternative activities [27]. Similar to lab experiments, field experiments start to include more ecological complexity in their natural resource dilemmas [28. $29,30,31,32,33,34]$. In contrast to lab experiments, studies find that cultural factors, experiences with specific institutional arrangements and ecological conditions can affect the way participants make decisions in those experiments $[26,29,32]$. This demonstrates that effectiveness of interventions is context specific.

A specific topic of interest in field experiments is the problem of crowding out $[35,36$, $\left.37,38^{* *}, 39 *\right]$. This means that imposing rules that would lead to cooperative solutions is followed lead to lower performance compared to voluntarily-agreed upon rules. This has implications for interventions, including payment for ecosystem services. Behavior motivated by moral obligations and social preferences can be undermined by economic interventions [38**]. However, a recent study in an authoritarian society shows that in some societies imposing behavior leads to higher compliance compared to self-governance [39*].

\section{Contemporary theory of collective action and the commons}

The accumulation of studies using various methods to study collective action and the commons during the last few decades has provided material for a revision of the theory. Poteete et al. [40] presents an alternative framework of collective action and the commons based on field studies and experiments and stress the importance of micro-situational variables, the broader context, and the relationship between them (Figure 2). The conventional theory was pristine in the simplicity of its model of human behavior. All individuals were thought to be selfish and rational. Individuals were assumed to have complete information about the structure of the situation they are in, including the preferences of other actors, the full range of possible actions, and the probability associated with each outcome resulting from a combination of actions.

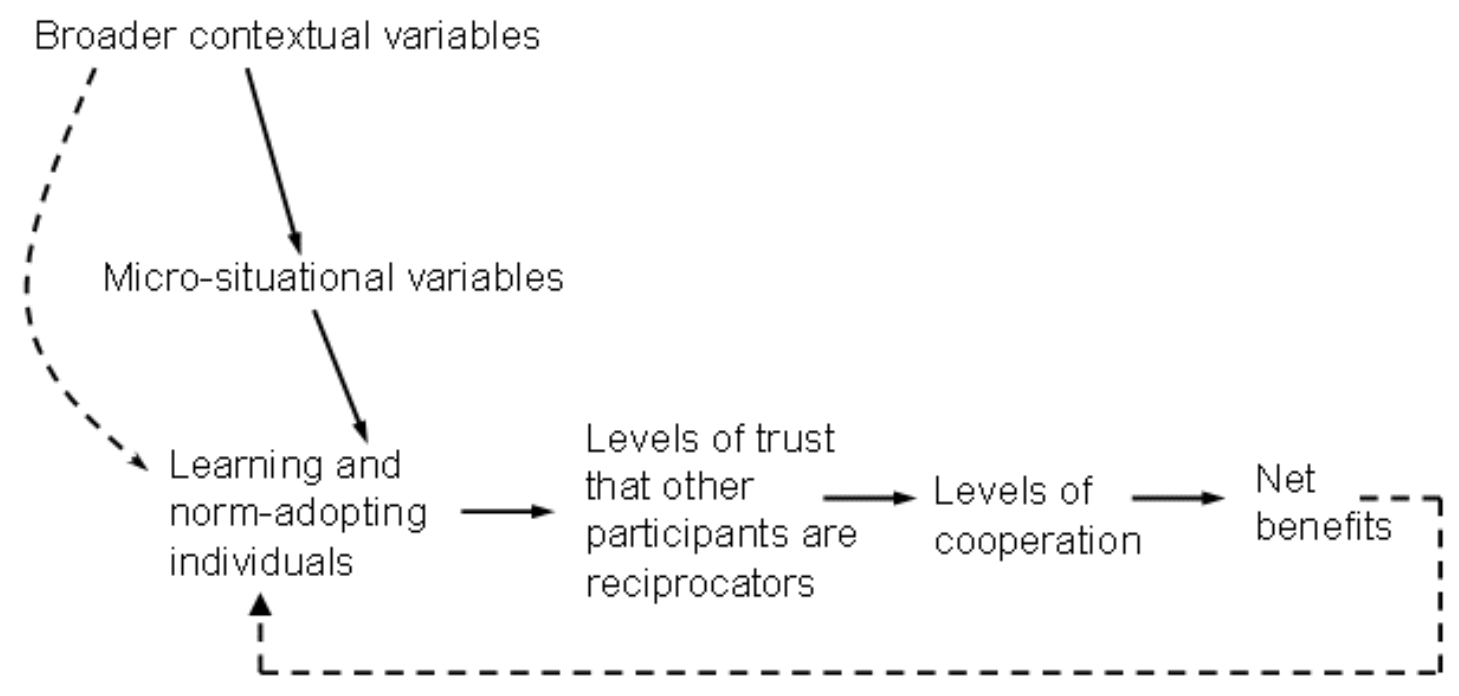

Figure 2: Conceptual framework of collective action where broader context and micro-situational variables affect the levels of trust and cooperation (based on Poteete et al. [40]). 
Decades of field work and experiments emphasized that not all humans behave like selfish rational beings, and that participants do not have complete information about all situations of interest to theorists. The alternative framework provided by Poteete et al. [40] is not complete but provides a starting point to identify the important attributes of action situations that need to be measured in empirical studies.

Instead of assuming selfish rational individuals maximizing a particular type of payoff function with complete information, analyses need to be based on assumptions about individuals who have imperfect knowledge, who learn and adopt norms, and who are influenced by microsituational and broader contextual variables. Especially important is the notion of other-regarding preferences and conditional cooperation. The majority of participants in experiments are classified as conditional cooperators [41]. They will cooperate in collective action situations if they expect others will do so too. This explains why communication - cheap talk - is so effective. Communication enables participants to signal their intensions and trustworthiness [12, 42]. Not only do participants cooperate if they expect that others will, they also value and receive emotional benefits if others receive good earnings too and that the earnings are fairly distributed among the participants [43, 44]. The assumptions that humans make in collective action situations and how incentives affect their decisions enable us to provide a more elaborate theoretical framework on the governance of the commons.

Poteete et al. [40] believe that behavior is more directly influenced by micro-situational variables, which in turn are influenced by the broader contextual variables (Figure 2). Examples of micro-situational variables include group size, heterogeneity among participants, reputation and time horizons. Larger groups will make it more difficult to evaluate the trustworthiness of all other participants and make it easier to free ride on actions of others. The various forms in which people can access information to judge trustworthiness and the reputation of others is important for the ability of groups to solve collective action problems.

Examples of broader contexts are policies at higher levels of organization, resource dynamics, history of social relationships and geography. What is the constitutional context, the cultural background and the physical geography in which decisions are made? And how are they influenced by price volatility at the world market, migration flows, climate change, and policy interventions $[45,46]$.

\section{Challenges ahead}

The majority of the work on collective action and the commons have been focused on small communities. There is a convincing amount of evidence that small communities are able to overcome the tragedy of the commons in the right context. But in a globalizing world there is an increasing interest in finding solutions to collective action problems at multiple levels of scale. You need to have global and national level policies for certain aspects of the solution, but you also need to nurture and stimulate local initiatives [47]. For a problem like climate change, local initiatives may focus on indicators appealing to the local level like carpooling to reduce air pollution, bicycling to improve health and using solar energy to reduce the energy bill.

In modern urbanized environments it will be more difficult to evaluate the trustworthiness of all other participants and make it easier to free ride on actions of others. The information that one can derive regarding the reputation of others can have an important influence of decision making. New information technologies reduce the costs to communicate with a larger number of people who are not necessarily physically co-located. For example, 
smart metering of water and energy use provides real time feedback on household consumption and compares this to the metrics of the neighborhood. We can learn from findings in social psychology about how to use descriptive norms to provide feedback that may keep conditional cooperators cooperating. An exemplar application is the use of social feedback on energy bills $[48,49,50]$.

The rapid information technology development makes it possible to derive real-time accurate information on the consequences of our decisions and the decisions of others. Increasingly people participate in various online social networks that make it possible to share and compare information and connect people with similar interests. This provides opportunities to scale up the strengths of self-governance as is observed in communities.

\section{Acknowledgements}

The author acknowledges financial support for this work from the National Science Foundation, grant numbers SES-0748632.

\section{References}

1. Hardin G: The Tragedy of the Commons: Science 1968, 162: 1243-1248.

2. Dasgupta P and Heal G: Economic Theory and Exhaustible Resources. Cambridge University Press: 1979.

3. Radovich J: The Collapse of the California Sardine Fishery-What Have We Learned? In Resource Management and Environmental Uncertainty: Lessons from Coastal Upwelling Fisheries. Edited by M Glantz, JD Thompson. Wiley: 1981: 107-136.

4. Myers RA, Hutchings JA, Barrowman NJ: Why Do Fish Stocks Collapse? The Example of Cod in Atlantic Canada. Ecological Applications 1997, 7: 91.

5. NRC (National Research Council): Proceedings of the Conference on Common Property Resource Management. National Academy Press: 1986.

6. Janssen MA: Elinor Ostrom (1933-2012) Nature 2012, 487: 172

7. Kiser L, Ostrom E: The Three Worlds of Action: A Metatheoretical Synthesis of Institutional Approaches. In Strategies For Political Inquiry. Edited by E Ostrom. Sage 1982: 179-222.

8. Ostrom E: Understanding Institutional Diversity. Princeton University Press: 2005.

* Seminal book that integrates insights from behavioral studies with institutional analysis of common pool resources

9. Ostrom E: Governing the Commons: The Evolution of Institutions for Collective Action. Cambridge University Press: 1990.

10. Cox M, Arnold G, Villamayor Tomás, S: A Review of Design Principles for Community-Based Natural Resource Management. Ecology and Society 2010: 15(4): 38. URL: http://www.ecologyandsociety.org/vol15/iss4/art38/.

11. Ostrom E, Gardner R, Walker J: Rules, Games and Common Pool Resources. University of Michigan Press: 1994.

12. Janssen MA, Holahan R, Lee A, Ostrom E: Lab Experiments for the Study of SocialEcological Systems. Science 2010, 328: 613-617. 
* Innovative computer based experiments that include spatial and temporal dynamics in commons experiments.

13. Camerer CF, Fehr E: When does “Economic Man” Dominate Social Behavior? Science 2006, 311: 47-52

14. Fehr E, Gächter S: 2000: Cooperation and Punishment in Public Good Experiments. American Economic Review 2000, 90(4): 980-994.

15. Guala F: Reciprocity: Weak or strong? What punishment experiments do (and do not) demonstrate. Behavioral and Brain Sciences 2012, 35:1-59

**Review of punishment literature that concludes that peer punishment is not the way cooperative communities solve the free-riders problem. Instead they coordinate punishment and reduce the cost and increase effectiveness.

16. Baldassarri D, Grossman G: Centralized sanctioning and legitimate authority promote cooperation in humans. Proceedings of the National Academy of Sciences USA 2011, 108: 11023-11027.

17. Reeson AF, Tisdell JG, McAllister RRJ: Trust, reputation and relationships in grazing rights markets: An experimental economic study. Ecological Economics 2011, 70(4): 651-658

18. Suter JF, Duke JM, Messer KD, Michael HA: Behavior in a Spatially Explicit Groundwater Resource: Evidence from the Lab. American Journal of Agricultural Economics 2012, 94(5): 1094-1112.

19. Holt CA, Johnson CA, Mallow CA, Sullivan SP: Water Externalities: Tragedy of the Common Canal. Southern Economic Journal 2012, 78(4): 1142-1162.

20. Seibert J, Vis MJP: Irrigania - a web-based game about sharing water resources. Hydrology Earth System Science 2012, 16: 2523-2530.

21. Kimbrough EO, Wilson BJ: Insiders, outsiders, and the adaptability of informal rules to ecological shocks. Ecological Economics 2013, 90: 29-40

22. Anderies, JM, Janssen MA, Lee A, Wasserman, H: Environmental variability and collective action: Experimental insights from an irrigation game. Ecological Economics 2013, 93: 166-176.

23. Janssen MA: The role of information in governing the commons: experimental results. Ecology and Society 2013, 18 (4): 4.

24. Li J, Michael HA, Duke J, Messer K, Suter J: Behavioral response to contamination risk information in a spatially explicit groundwater environment: Experimental evidence. Water Resources Research in press

25. Rustagi D, Engel S, Kosfel M: Conditional Cooperation and Costly Monitoring Explain Success in Forest Commons Management. Science 2010, 330: 961-965

** Demonstration of external validity of field experiments. Behavior in experiments by community members is a good predictor of success in forestry management program.

26. Gelcich S, Guzman R, Rodriguez-Sickert C, Castilla JC, Cárdenas JC: Exploring external validity of common pool resource experiments: insights from artisanal benthic fisheries in Chile. Ecology and Society 2013, 18(3): 2. 
27. Cardenas JC: Experiments in Environment and Development. Annual Review of Resource Economics 2009, 1: 157-182.

28. Travers H, Clements T, Keane A, Milner-Gulland EJ: Incentives for cooperation: The effects of institutional controls on common pool resource extraction in Cambodia. Ecological Economics 2011, 71(15): 151-161

29. Prediger S, Vollan B, Frölich M: The impact of culture and ecology on cooperation in a common-pool resource experiment. Ecological Economics 2011, 70(9): 1599-1608

30. Cardenas JC, Rodriguez LA, Johnson N: Collective action for watershed management: field experiments in Colombia and Kenya. Environment and Development Economics 2011, 16(3): 275-303.

31. Janssen MA, Bousquet F, Cardenas JC, Castillo D, Worrapimphong K: Field Experiments of Irrigation Dilemmas. Agricultural Systems 2012, 109: 65-75.

32. Ghate R, Ghate S, Ostrom, E: Cultural norms, cooperation, and communication: Taking experiments to the field in indigenous communities. International Journal of the Commons 2013, 7(2): 498-520.

33. Pfaff A, Velez MA, Taddei R, Broad K: Unequal Information, Unequal Allocation: Bargaining field experiments in NE Brazil. Environmental Science \& Policy 2013, 26: 90-101.

34. Otto IM, Wechsung F: The effects of rules and communication in a behavioral irrigation experiment with power asymmetries carries out in North China. Ecological Economics 2014, 99:10-20.

35. Cardenas JC, Stranlund J, Willis C: Local environmental control and institutional crowding out, World Development 2000, 28(10): 1719-1733.

36. Vollan, B: Socio-ecological explanations for crowding-out effects from economic field experiments in southern Africa. Ecological Economics 2008, 67(4): 560-573.

37. Kerr J, Vardhan M, Jindal R: Prosocial behavior and incentives: Evidence from field experiments in Mexico and Tanzania. Ecological Economics 2012, 73: 220-227.

38. Bowles, S. and Polanía-Reyes S: Economic Incentives and Social Preferences: Substitutes or Complements. Journal of Economic Literature 2012, 50:2, 368-425

**Reviews literature how explicit economic incentives designed to increase contributions to public goods sometimes are counterproductive or less effective than would be predicted among entirely self-interested individuals.

39. Vollan B, Zhou Y, Landmann A, Hu B, Herrmann-Pillath C: Cooperation under democracy and authoritarian norms. Working Papers in Economics and Statistics 2013-14, University of Innsbruck

*Experimental results show that negative effects of imposing rules, compared to voting for rules, do not hold in a society with authoritarian norms.

40. Poteete AM, Janssen MA, Ostrom E: Working Together: Collective Action, the Commons and Multiple Methods in Practice. Princeton University Press: 2010.

41. Fischbacher U, Gächter S, Fehr E: Are People Conditionally Cooperative? Evidence From a Public Goods Experiment. Economics Letters 2001, 71(3): 397-404. 
42. Janssen MA, Tyson M, Lee A: The effect of constrained communication and limited information in governing a common resource. International Journal of the Commons in press.

43. Green J: Moral Tribes: Emotion, Reason, and the Gap between us and them. Penguin Press 2013.

44. Fehr E, Camerer CF: Social neuroeconomics: the neural circuitry of social preferences. Trends in Cognitive Sciences 2007. 11(10): 419-427.

45. Anderies JM, Janssen MA: Robustness of Social-Ecological Systems: Implications for Public Policy. Policy Studies Journal 2013, 41(3): 513-536.

46. Anderies JM, Janssen MA: The fragility of robust social-ecological systems. Global Environmental Change 2011, 21: 1153-1156.

47. Ostrom E: Nester Externalities and Polycentric Institutions: Must We Wait for Global Solutions to Climate Change Before Taking Actions at Other Scales? Economic Theory 2012, 49(2): 353-369.

48. Schultz P, Wesley N, Cialdini JM, Goldstein RB, Noah J, Griskevicius V: The Constructive, Destructive, and Reconstructive Power of Social Norms. Psychological Science 2007, 18(5): 429-434.

49. Allcott H: Social Norms and Energy Conservation. Journal of Public Economics 2011, 95(9-10): 1082-1095.

50. Costa DL, Kahn ME: Energy Conservation "Nudges" and Environmentalist Ideology: Evidence from a randomized residential electricity field experiment. Journal of the European Economic Association 2013, 11(3): 680-702.

*Field experiment among 35,000 Californian households show that providing feedback on households energy use compared with their neighbors leads to energy use reduction, but the effect is higher among households with a liberal political ideology 